\title{
Tropical Cyclone Formation in Environments with Cool SST and High Wind Shear over the Northeastern Atlantic Ocean*
}

\author{
RACHEL G. MAUK AND JAY S. HOBGOOD \\ Atmospheric Sciences Program, The Ohio State University, Columbus, Ohio
}

(Manuscript received 2 May 2011, in final form 26 June 2012)

\begin{abstract}
Tropical cyclones with nontropical characteristics are being identified more frequently over the North Atlantic Ocean in recent years. These systems present forecasting challenges because of their hybrid structure. The authors analyze environmental conditions preceding the formation of 20 late-season northeastern Atlantic tropical cyclones identified during the 1975-2005 seasons. A recent tropical storm, Grace (2009), is discussed as a case study. Seventeen of the 20 systems originated from nontropical systems (surface low, frontal weak, and frontal strong). Three tropical cyclones experienced nontropical influences during development despite originating from tropical waves. Ambient sea surface temperatures, relative vorticity, vertical temperature profiles, and wind shear are investigated to identify conditions conducive to tropical cyclone formation. Tropical cyclones developing from nontropical precursors form in environments distinct from the classical tropical cyclone environment. For 17 systems, sea surface temperatures are cooler than $26^{\circ} \mathrm{C}$. Stability analysis suggests that convection is shallow. Wind shear decreases for the 850-300-hPa layer in comparison to the $850-200-\mathrm{hPa}$ layer. Most systems still experience shear in excess of $8 \mathrm{~m} \mathrm{~s}^{-1}$ for the 850 $300-\mathrm{hPa}$ layer. It is suggested that late-season tropical cyclones in this region are shallower in vertical extent than typical tropical cyclones, which reduces the impact of strong wind shear in the 850-200-hPa layer.
\end{abstract}

\section{Introduction}

In a season marked by record-shattering extremes in tropical cyclone (TC) number and intensity, the end of the 2005 Atlantic hurricane season was no less unusual. While TC activity in the tropics finally ceased by the fourth week of November, the last three TCs (Delta, Epsilon, and Zeta) formed in the eastern Atlantic Ocean during the final six weeks of 2005 . In addition to the timing, these three systems were unusual in their development and structure. They were initially baroclinic systems that subsequently transformed into tropical systems. (A fourth TC, Vince, formed in early October southeast of the Azores from an occluded low and struck Spain as a tropical depression.) Despite the tropical

\footnotetext{
* Supplemental information related to this paper is available at the Journals Online website: http://dx.doi.org/10.1175/WAF-D-1100048.s1.

Corresponding author address: Rachel G. Mauk, Atmospheric Sciences Program, The Ohio State University, 1036 Derby Hall, 154 North Oval Mall, Columbus, OH 43210.

E-mail:mauk.20@osu.edu
}

classification by the National Hurricane Center (NHC), all four TCs maintained some nontropical features after transition (Beven et al. 2008). TCs retaining nontropical characteristics are sometimes called hybrid TCs or hybrid cyclones (e.g., Hart 2003; Davis and Bosart 2004; Hulme and Martin 2009a).

Forecasting hybrid TCs like the 2005 quartet requires understanding both subtropical cyclones and TCs. Simpson (1952) noted that subtropical kona cyclones could acquire the wind and rainfall patterns of TCs, suggesting that a system's position on the cyclone structure continuum was unfixed. Hart (2003) first referred to subtropicalto-tropical evolution as tropical transition (TT). Evans and Guishard (2009) found that from 1998 to 2004, 15 of 18 Atlantic subtropical cyclones completed TT, confirming that TT is an important development mechanism in this basin.

As long ago as 1951, TCs were reported that did not completely fit the tropical definition. Moore and Davis (1951) analyzed a TC, eventually named Able, which formed in mid-May 1951 east of Daytona Beach, Florida. Able became a 100-kt hurricane offshore of the Carolinas. The authors declared this TC exceptional because of its location (so close to the U.S. coast in the 
off season) as well as its apparent structure. They also stated that hurricane-like systems had been observed over the subtropical Atlantic Ocean in winter. Erickson (1967) described Hurricane Dorothy (1966) as a hybrid cyclone. Dorothy formed underneath a vigorous upperlevel trough and over sea surface temperatures (SST) of $25^{\circ}-26^{\circ} \mathrm{C}$, a scenario very similar to the formation of Hurricane Able. However, forecasters were able to track the evolving structure of Dorothy with satellite imagery. Dorothy developed the classic miniature-occluded cyclone structure. Outer convection dissipated as the central convection deepened. A weak warm core developed, and the system eventually appeared to have attained a fully tropical structure. In HURDAT (Jarvinen et al. 1984), the Atlantic Best Track Dataset maintained by National Hurricane Center (NHC), Dorothy and Able were identified as TCs through their initial development.

Much research on TT has involved analyzing systems using potential vorticity (PV) methods (Bosart and Bartlo 1991; Davis and Bosart 2003; McTaggart-Cowan et al. 2006b, 2008; Hulme and Martin 2009a,b). Bosart and Bartlo (1991) analyzed the development of Hurricane Diana (1984), which formed just east of Florida along an old front and eventually became a TC. They determined that the development and transition process had three steps. First, a PV maximum triggered development of a wave cyclone along the front. Second, strong surface and latent heat fluxes supported convection in the northeast flow along the front. Third, positive PV advection created a favorable environment for organizing the convection around the subtropical cyclone.

Case studies abound in TT research. Pezza and Simmonds (2005) and McTaggart-Cowan et al. (2006a) analyzed Hurricane Catarina (2004), the first known hurricane in the southern Atlantic Ocean. Both papers concluded Catarina formed within an unusually favorable thermodynamic environment for TT. Hulme and Martin (2009a) analyzed six cases of TT. In each case, the precursor extratropical cyclone developed from the interaction between a surface baroclinic zone and an upper-level trough. An occluded cyclone developed, and low static stability and strong frontogenesis were conducive to convection at its center. The convection decreased the upper-level PV and increased the boundary layer PV, enhancing diabatic heating and triggering TT.

Modeling and PV arguments have helped to improve the understanding of the TT process, yet little is known about the local environmental conditions during which TT occurs. Knowledge of the dynamic and thermodynamic environments in the hours prior to formation may help with our understanding of the structure of such systems, which in turn may help to improve forecasts of their intensity. The northeastern Atlantic basin is not known as a hospitable region for TC formation. How, then, do TCs form in this environment? Do the generally accepted necessary conditions for tropical cyclogenesis (e.g., Gray 1968) apply to all TCs, even those from nontropical origins? What characteristics distinguish TCs with the most nontropical origins?

This article will describe environmental conditions immediately preceding the formation of 21 late-season northeastern Atlantic TCs. Section 2 summarizes the data used in this research. An overview of the study set, including the classification scheme, is presented in section 3. Environmental conditions observed with the systems are discussed in section 4. In section 5, Tropical Storm Grace (2009) is presented as a case study of lateseason TC formation in the study region. Section $6 \mathrm{ex}-$ amines the results from a forecasting perspective and proposes a mechanism for TC formation in this environment. Last, section 7 presents a synthesis of the environmental conditions for late-season TC formation over the northeastern Atlantic Ocean.

\section{Data and methods}

To standardize comparisons of TCs with tropical origin with TCs of baroclinic origin, formation is defined as the time that the system was classified as tropical by NHC in HURDAT with maximum sustained winds of $35 \mathrm{kt}$ or greater. This definition minimizes the impact of technological and operational changes due to improvements in satellites and the evolution of the Dvorak (1975) and Hebert-Poteat (Hebert and Poteat 1975) techniques. This study examines TCs during the period of 1975-2005, when tropical and subtropical cyclones are distinguished through objective satellite classification. Subtropical storms that were never classified as TCs are excluded from this study. [For a brief overview of factors involved in classifying a TC from nontropical origins, refer to Vince (2005) discussion 1, available at www.nhc.noaa.gov/archive/2005/dis/al232005.discus.001. shtml.] The focus of TC development is limited here to the time range of 1 October-31 December, chosen to reflect the period of 2005 in which TCs Vince, Delta, Epsilon, and Zeta were observed. The area of focus is limited to the region of the Atlantic Ocean north of $20^{\circ} \mathrm{N}$ and east of $60^{\circ} \mathrm{W}$. The 20 TCs selected for study are listed in Table 1, and the formation locations are shown in Fig. 1.

HURDAT coordinates, intensities, and classifications are used when available. To capture the conditions present during TC formation, data are collected for each system during the $30 \mathrm{~h}$ prior to TC classification (hereafter $T-30$ ). For eight systems (a total of 23 points), the HURDAT record does not span the required $30 \mathrm{~h}$. For 
TABLE 1. TCs in the study set (first 20), plus a case study (Grace 2009). Columns from left to right are TC name, label for graphics, the date and time of formation $(T-0), T-0$ latitude and longitude, the intensity at formation, the first study time available in HURDAT, and the type.

\begin{tabular}{|c|c|c|c|c|c|c|c|}
\hline $\mathrm{TC}$ & Label & $\begin{array}{l}\text { Date and time of } \\
\text { formation }(T-0)\end{array}$ & Lat $\left({ }^{\circ} \mathrm{N}\right)$ & Lon $\left({ }^{\circ} \mathrm{W}\right)$ & $\begin{array}{l}\text { Intensity } \\
\quad(\mathrm{kt})\end{array}$ & $\begin{array}{l}\text { First time in } \\
\text { HURDAT }\end{array}$ & Type \\
\hline Holly & $\mathrm{H} 76$ & 1800 UTC 23 Oct 1976 & 22.5 & 58.0 & 35 & $T-24$ & TW \\
\hline Irma & $\mathrm{I} 78$ & 1200 UTC 4 Oct 1978 & 35.1 & 31.5 & 40 & $T-30$ & SL \\
\hline Ivan & I80 & 1800 UTC 4 Oct 1980 & 35.6 & 24.6 & 40 & $T-30$ & FW \\
\hline Karl & K80 & 1800 UTC 25 Nov 1980 & 37.7 & 44.7 & 65 & $T-18$ & FS \\
\hline Jose & J81 & 0000 UTC 30 Oct 1981 & 27.7 & 46.6 & 35 & $T-12$ & FW \\
\hline Lili 1984 & L84 & 1200 UTC 20 Dec 1984 & 31.1 & 52.4 & 70 & $T-30$ & FS \\
\hline Lili 1990 & L90 & 0000 UTC 11 Oct 1990 & 31.2 & 55.9 & 65 & $T-30$ & FS \\
\hline Florence & F94 & 0000 UTC 4 Nov 1994 & 26.0 & 52.6 & 35 & $T-30$ & FW \\
\hline Tanya & T95 & 1200 UTC 27 Oct 1995 & 26.2 & 57.9 & 35 & $T-12$ & TW \\
\hline Nicole & N98 & 0600 UTC 24 Nov 1998 & 27.9 & 29.1 & 35 & $T-6$ & FW \\
\hline Nadine & N00 & 1200 UTC 20 Oct 2000 & 30.4 & 57.2 & 35 & $T-24$ & TW \\
\hline Lorenzo & L01 & 0000 UTC 30 Oct 2001 & 28.5 & 44.6 & 35 & $T-30$ & SL \\
\hline Noel & N01 & 1200 UTC 5 Nov 2001 & 37.8 & 50.3 & 65 & $T-30$ & FS \\
\hline Olga & $\mathrm{O} 01$ & 1200 UTC 24 Nov 2001 & 29.5 & 49.8 & 50 & $T-30$ & FW \\
\hline Peter & $\mathrm{P} 03$ & 0600 UTC 9 Dec 2003 & 20.0 & 37.4 & 40 & $T-30$ & FW \\
\hline Otto & $\mathrm{O} 04$ & 1800 UTC 30 Nov 2004 & 31.7 & 51.0 & 40 & $T-30$ & FW \\
\hline Vince & V05 & 1200 UTC 9 Oct 2005 & 33.8 & 19.3 & 55 & $T-30$ & FW \\
\hline Delta & Del05 & 1200 UTC 23 Nov 2005 & 27.4 & 41.2 & 50 & $T-30$ & FS \\
\hline Epsilon & Ep05 & 0600 UTC 29 Nov 2005 & 31.5 & 49.2 & 45 & $T-0$ & FW \\
\hline Zeta & $\mathrm{Z} 05$ & 0600 UTC 30 Dec 2005 & 24.2 & 36.1 & 40 & $T-6$ & FW \\
\hline Grace & G09 & 0600 UTC 4 Oct 2009 & 38.5 & 29.5 & 40 & $T-30$ & FW \\
\hline
\end{tabular}

22 of these points, centers are estimated using Geostationary Operational Environmental Satellite (GOES) and Meteosat infrared (IR) satellite imagery. No satellite imagery is available for Holly (1976) at $T-30$. For this time, coordinates are extrapolated from the existing
HURDAT points at $T-24$ and $T-18$. Grid boxes used in the analysis are centered on the grid point closest to the system's location at each time. Some uncertainty is inherent in these location estimates because of the angle of the satellite imagery and the disorganization of some

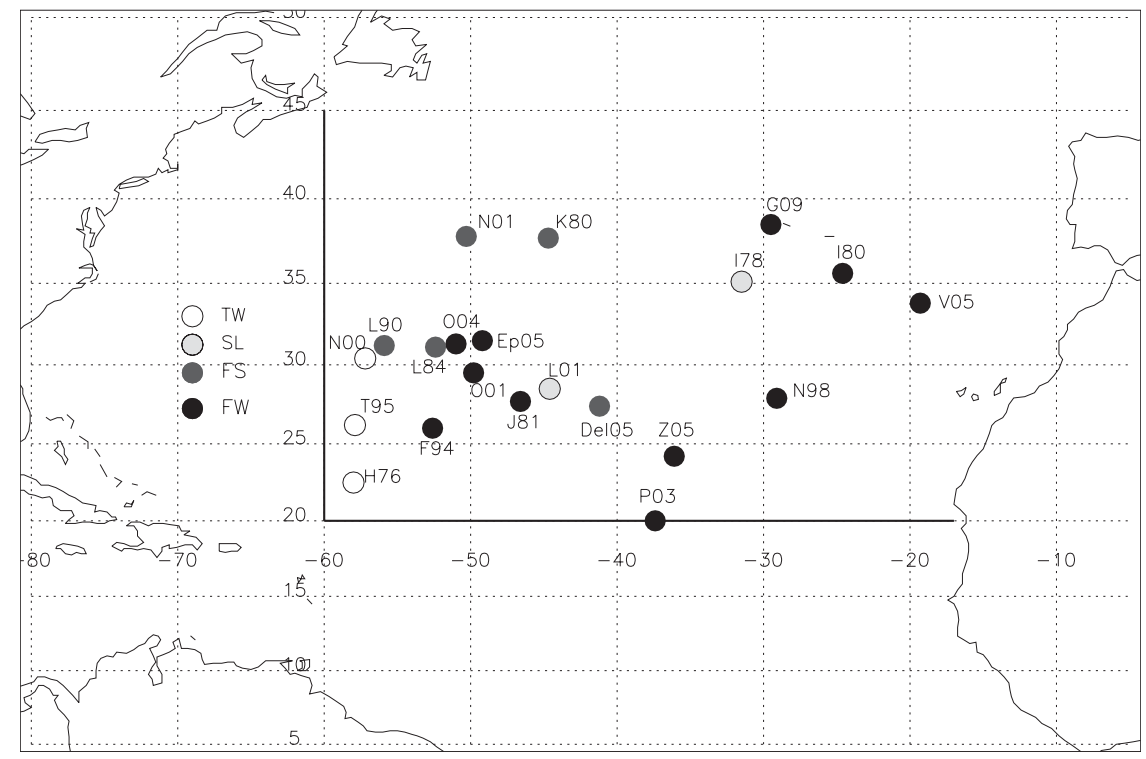

FIG. 1. Formation locations of 21 late-season TCs and their notations listed in Table 1. Grace (2009) is discussed as a case study in section 5. Dark lines demarcate the study region (the Atlantic Ocean north of $20^{\circ} \mathrm{N}$ and east of $60^{\circ} \mathrm{W}$ ). 
systems at earlier times. However, the extent of the grid boxes (explained subsequently) reduces the impact of this error.

Reynolds OIv. 2 weekly $1^{\circ}$ gridded SST fields (Reynolds et al. 2002) are used for systems occurring after 1981. SST is averaged over a $5^{\circ}$ square box around the system's location. Five TCs-Holly (1976), Irma (1978), Ivan (1980), Karl (1980), and Jose (1981)—occurred prior to the start of the Reynolds weekly dataset. For these systems, the National Oceanic and Atmospheric Administration/National Climatic Data Center's (NOAA/NCDC) Extended Reconstructed Sea Surface Temperature (ERSST) version $3 \mathrm{~b}$ dataset is used (Smith et al. 2008). Weekly values for these systems are interpolated from the ERSST monthly means. These data are gridded every $2^{\circ}$, so SST is averaged for a $4^{\circ}$ square box. Anomalies relative to the $1971-$ 2000 mean are also analyzed for each period.

ERSST and Reynolds SST are compared for the systems forming after 1981 to check consistency between datasets. The average absolute difference between the two SSTs for each system is $0.3^{\circ} \mathrm{C}$, and all but one system differs by $0.5^{\circ} \mathrm{C}$ or less. Most Reynolds SSTs are warmer than the ERSST results. The greatest outlier is Noel (2001), which is $1.1^{\circ} \mathrm{C}$ warmer in the Reynolds dataset than in ERSST. We attribute this large difference to the week chosen for the Reynolds SST. The $T-30$ for Noel (0600 UTC 4 November 2001) falls on the first day of the Reynolds weekly average, so to minimize the effect of the TC-induced cold wake, the previous week's data (28 October-3 November 2001) are used.

NCEP-National Center for Atmospheric Research (NCAR) data (Kalnay et al. 1996) are available on a $2.5^{\circ}$ grid at 6-h intervals from 1 January 1948 to the present. Air temperature, relative humidity, specific humidity, surface pressure, and wind ( $u$ and $v$ components) data are extracted from this dataset. Ambient environmental temperatures are computed by averaging the values over a $10^{\circ}$ square system-centered box at 12 levels: 0.995 sigma, 925, 850, 700, 600, 500, 400, 300, 250, 200, 150 , and $100 \mathrm{hPa}$. The 0.995 sigma temperature is the closest available level to the surface temperature. Most 0.995 sigma temperatures are cooler than the corresponding SSTs. Near-surface air temperatures have been observed to exceed the SST in occluded maritime cyclones (Simpson and Hope 1972; Kitabatake 2008), so data are not filtered. Vertical shear of the horizontal wind is calculated for the $850-300-$ and $850-200-\mathrm{hPa}$ layers on a $5^{\circ}$ square box using the point nearest the system's position as the box's center. The boundaries of this box exactly match those for the Reynolds SST box.

A larger box is chosen for thermodynamic variables relative to the $u$ and $v$ wind to better capture the ambient environment. Weaker systems can be challenging to locate in satellite imagery, especially at $T-30$. Some systems are displaced from the reanalysis point closest to the HURDAT coordinates. The larger box helps to account for these issues. Equilibrium level (EL) and convective available potential energy (CAPE) were calculated for both the box-average temperature profile and at the reanalysis points immediately to the northeast, southeast, southwest, and northwest of the center point of the box. An explanation of the method used to calculate EL and CAPE is available in the supplemental material online (http://dx.doi.org/10.1175/WAF-D-1100048.s1), and tables of both the box and quadrant averages for EL (Table S1) and CAPE (Table S2) are available as well (http://dx.doi.org/10.1175/WAF-D-1100048.s2).

\section{Overview of classification scheme}

Before discussing the classification scheme developed here, we wish to discuss previous work on classifying hybrid TCs. Diagnosing extratropical transition was the purpose of Hart (2003), though it has also been used to identify TT. Cyclone phase space (CPS) diagrams are thermodynamically based, using horizontal symmetry and vertical structure to differentiate cyclones. CPS can be applied to a cyclone at any point in its life, hence its relevance to forecasting structural transformations.

Davis and Bosart (2004) explicitly differentiate TT cases using the dynamic criterion of intensity relative to wind-induced surface heat exchange (WISHE; Emanuel 1986) during TT. They define two categories of systems undergoing TT: strong extratropical cyclone (SEC) systems are sufficiently intense to support WISHE, while weak extratropical cyclone (WEC) systems are too weak to support WISHE. These categories are applicable throughout the TT period, and it is possible for a system to move between categories over the course of its existence.

The work of McTaggart-Cowan et al. (2008) is also thermodynamically based, using baroclinicity at the low and upper levels to differentiate developing TCs. This scheme is applied to the system at the start of the HURDAT record. For hybrid systems, this time may be hours to days prior to TC classification. Strong TT and weak TT are consistent with SEC and WEC, respectively, from Davis and Bosart (2004).

In this study, the 20 TCs were distributed into four categories using NHC tropical cyclone reports, satellite imagery, and local relative vorticity maxima: those that develop from tropical waves (TWs), from nontropical surface lows (SLs), from strong frontal systems (FSs), and from weak frontal systems (FWs). The SL, FS, and FW categories subdivide the SEC-strong TT categories mentioned earlier. In contrast to previous schemes, the 


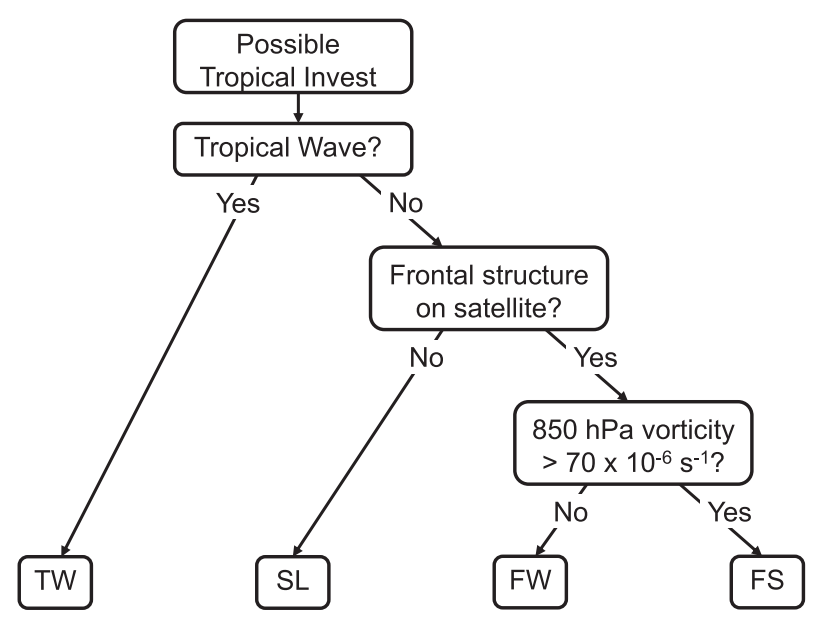

FIG. 2. Flowchart describing the classification process. A potential TC in the region is evaluated on up to three criteria to arrive at the classification: origin, evidence of frontal structure, and $850-\mathrm{hPa}$ vorticity.

classifications of this work combines dynamic and thermodynamic criteria, and are based on system characteristics from the $30 \mathrm{~h}$ immediately preceding $\mathrm{TC}$ formation.

Figure 2 presents a flowchart of the classification process. Systems are classified based on origin (tropical or nontropical), the presence of fronts (a proxy for baroclinicity), and the depth of the cyclonic vortex. Tropical cyclone reports are consulted to identify which systems had tropical origins and which had nontropical origins. IR satellite imagery is used to detect frontal structures, which are not always evident in the reanalysis data. Imagery also helps to account for differences in the rate of development of individual systems.

The maximum relative vorticity for $T-30$ at 850 and $500 \mathrm{hPa}$ observed within $10^{\circ}$ of the system's location is plotted in Fig. 3. $T-30$ was chosen to capture the developing TC's vortex structure. Figure 3 shows the relative strengths of the low- and midlevel circulations, which relate to the environments in which the systems are observed. Vorticity thresholds for each category are plotted in Fig. 3 (dotted lines) and are based on vorticity maxima from reanalysis data. Explanations for the relative magnitudes are provided in the description of each category later in this section. If time is limited, a forecaster potentially could use the vorticity thresholds to classify the system. Example satellite images of each type at $T-12$ are presented in Fig. 4 and are discussed in the following subsections.

Three systems are classified as TW based on tropical cyclone reports: Holly (1976), Tanya (1995), and Nadine (2000). Figure 3 also supported a separate type for these systems because their $T-30$ vorticity maxima at $500 \mathrm{hPa}$ are only about $20 \times 10^{-6} \mathrm{~s}^{-1}$.
Three systems have weak vorticity maxima at both 850 and $500 \mathrm{hPa}$ : Irma (1978), Lorenzo (2001), and Olga (2001). In satellite imagery, Irma and Lorenzo consist of discrete but poorly organized convection with no frontal structures evident during the $30 \mathrm{~h}$ prior to formation (Fig. 4b). These two systems compose the SL category. Figure 5 (top row) is a series of satellite images for Olga (2001) at $T-24$ (Fig. 5a), $T-12$ (Fig. 5b), and $T-0$ (Fig. 5c). Olga developed from an extratropical low that spun up along a frontal boundary. The low values of 500-hPa relative vorticity at $T-30$ indicate that the rapidly forming circulation has yet to translate upward (Beven et al. 2003). Rapid development is not observed in any other case; however, the possibility of rapid development is noted. Olga is therefore placed in the FW category.

The remaining 14 systems developed from nontropical origins. All have prominent $500-\mathrm{hPa}$ relative vorticity maxima exceeding $40 \times 10^{-6} \mathrm{~s}^{-1}$ (Fig. 3), likely due to their development from established extratropical cyclones. Most can be tracked in satellite imagery for several days prior to formation. Three distinct precursors are identified in the satellite imagery based on cloud patterns. The most common precursor is an occluding cyclone: the TC forms at the cyclone center, where the local temperature gradient is reduced. The other two precursors are traced to lows with frontal structures. If TT occurs slowly, the low fully separates from the associated frontal structure before being classified as a TC. If TT occurs quickly, the low may not fully separate from the associated frontal structure before being classified as a TC.

The term frontal is used in the sense that FS and FW systems have an existing center of low pressure, yet still exhibit frontal structures. The strength of the 850-hPa circulation distinguishes the FS and FW subtypes. Systems with strong low-level circulations at $T-30$ (850-hPa relative vorticity maxima exceeding $70 \times$ $10^{-6} \mathrm{~s}^{-1}$; Fig. 3) are both stronger in intensity and have better-organized convection, and are treated as a distinct type of developing TC.

\section{a. Tropical wave $(T W)$}

TW systems develop from tropical waves, mostly following the classical tropical development process (e.g., Emanuel 1991). TW systems develop in the southwestern corner of the region in late October (Fig. 1, Table 1). Low- and midlevel circulations are weak, consistent with development from tropical disturbances. Unlike typical TCs, the three TW systems in the study set-Holly (1976) (Lawrence 1977), Tanya (1995; Fig. 4a) (Lawrence et al. 1998), and Nadine (2000) (Franklin et al. 2001)_form in the vicinity of an upper-level cyclone or trough. Thus, 


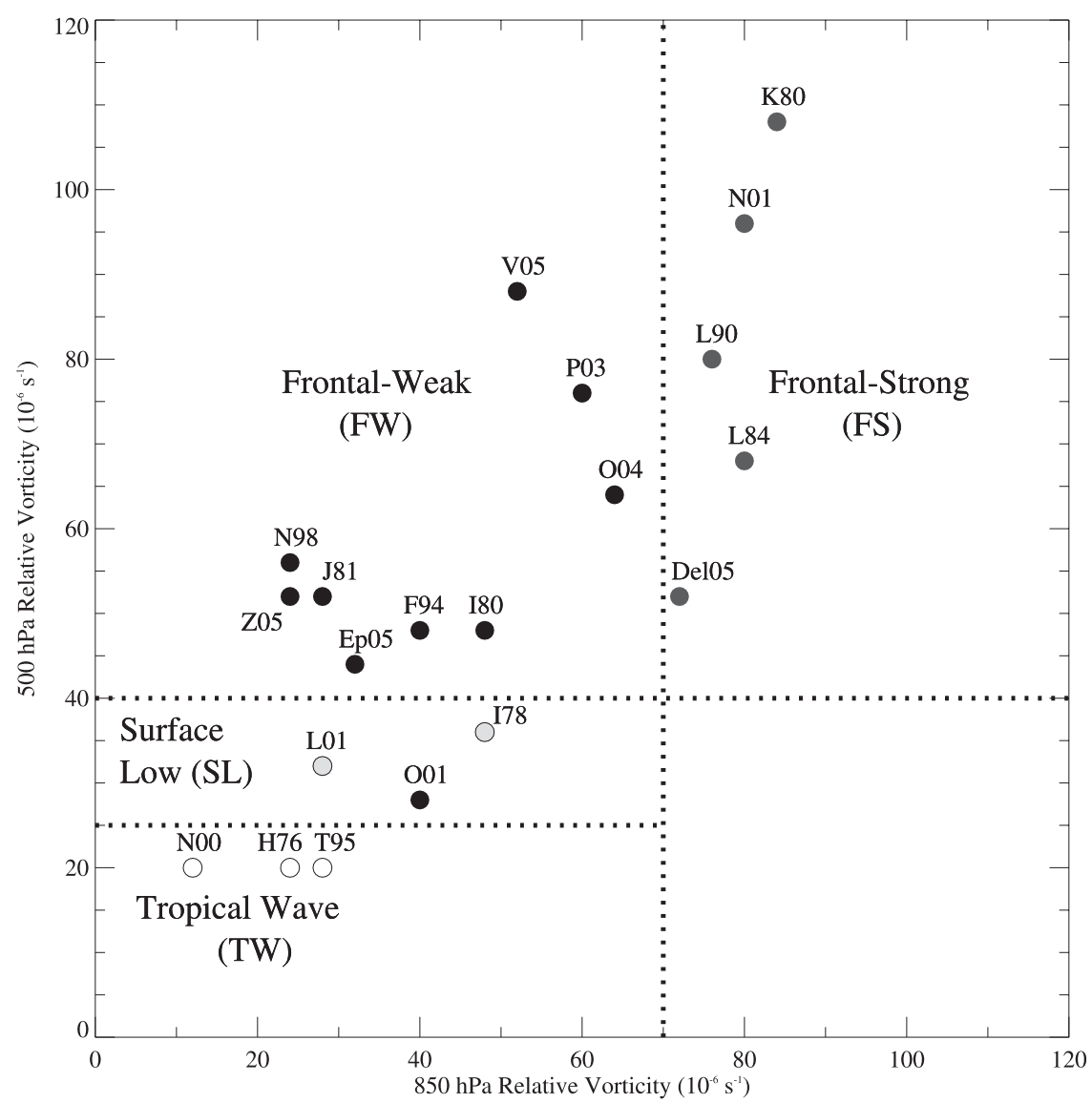

FIG. 3. Maximum $T-30$ relative vorticity at 850 and $500 \mathrm{hPa}$ in the vicinity of the developing TCs. Dotted lines represent thresholds for each type based on the study set. Symbol shading and notation as in Fig. 1.

baroclinic influences are likely even among the most tropical systems in this region. TW systems are most consistent with the transient-trough category of McTaggartCowan et al. (2008). Holly (1976) and Tanya (1995) eventually became hurricanes, and Nadine (2000) peaked as a strong tropical storm.

\section{b. Nontropical surface low (SL)}

Only two systems fit the SL subtype. Irma (1978) and Lorenzo (2001; Fig. 4b) were weak and short-lived TCs. Both formed in the east-central Atlantic basin, Irma in early October and Lorenzo in late October. The $850-\mathrm{hPa}$ circulation is slightly stronger than for TW systems, but weaker than for frontal precursors. A broad 500-hPa vorticity maximum exists over the low-level center (Fig. 3). SL systems form when a surface-based gale center encounters a relatively moist low-level environment with moderate environmental lapse rates. Convection briefly organizes into a weak tropical storm, but the mid- and upper-level portions of the TC never strengthen. An approaching extratropical cyclone quickly absorbs the TC. These systems, while weaker than those of FW and FS, originate from sufficiently intense extratropical cyclones to be SEC and strong TT cases.

\section{c. Frontal-strong (FS) systems}

FS systems are near their peak intensity at the time of TT. They develop in the northwestern section of the study region and are spread in time from early October to mid-December (Fig. 1, 4c; Table 1). Strong vorticity maxima occur at both 850 and $500 \mathrm{hPa}$ (Fig. 3). Symmetrical convection around the low-level center suggests a strong system. Although the convection associated with the incipient TC is distinct and well organized in the satellite imagery, frontal boundaries from the parent system are still identifiable.

One FS system, Karl (1980), was unusual even for the northeastern Atlantic Ocean (Lawrence and Pelissier 1981). Figure 5 (bottom row) is a series of satellite images of Karl for $T-24, T-12$, and $T-0$. A small area of concentrated convection developed at the core of a large occluding low $(T-24 ;$ Fig. 5d). A small eyelike 

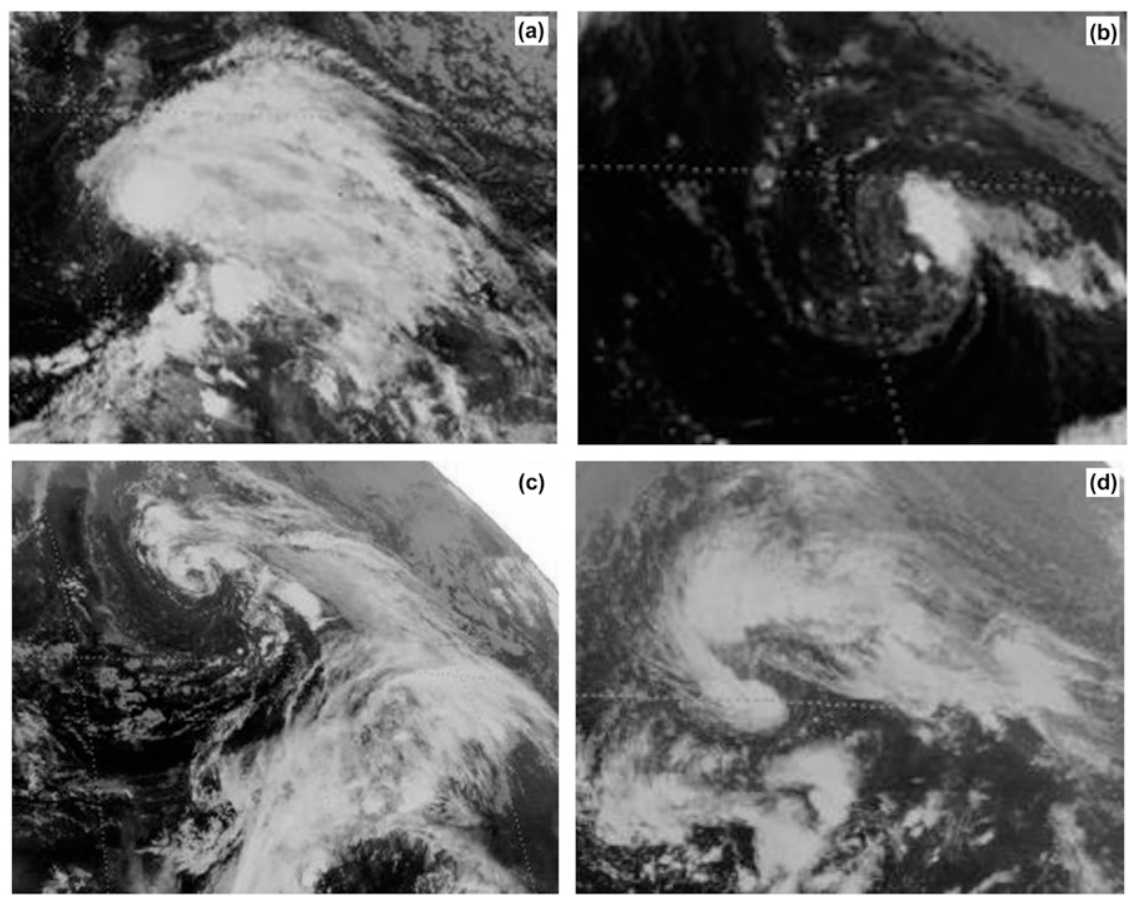

FIG. 4. Example IR satellite images for each type at $T$ - 12: (a) TW (Tanya, 0000 UTC 27 Oct 1995), (b) SL (Lorenzo, 1200 UTC 29 Oct 2001), (c) FS (Noel, 0000 UTC 5 Nov 2001), and (d) FW (Epsilon, 1800 UTC 28 Nov 2005).

feature appeared within this convection center early on 25 November 1980, and the core system was declared a TC a few hours later ( $T-0$; Fig. 5f). The parent frontal system was still discernible to the north and east of the TC. Karl eventually merged with an upstream frontal system. Only two other TCs have been documented with a similar developmental pathway: the Unnamed Hurricane (1991) (Pasch and Avila 1992) and Tropical Storm Grace (2009) (Berg and Avila 2011).

\section{d. Frontal-weak $(F W)$ systems}

Containing $10 \mathrm{TCs}$, the FW group is the largest of the four categories. FW systems were spread across the region from early October to late December (Figs. 1 and 4d; Table 1). Six systems formed during the 2001-05 seasons. Some systems (e.g., Florence in 1994) formed in nearly tropical environments, while others were marginally too weak in $850-\mathrm{hPa}$ vorticity to be included in the FS category (e.g., Peter in 2003). FW transition intensities minimally related to peak intensities. Ivan (1980) and Florence (1994) eventually became category 2 hurricanes after transitioning at $35 \mathrm{kt}$, yet Otto (2004) never strengthened more than $10 \mathrm{kt}$ above its $35-\mathrm{kt}$ transition intensity. Three systems-Peter (2003), Otto (2004), and Vince (2005)—had larger vorticity maxima than the other FW systems at both 850 and $500 \mathrm{hPa}$. All three were tracked in HURDAT as subtropical storms for at least $36 \mathrm{~h}$ prior to formation, and had maximum sustained winds of $40 \mathrm{kt}$ at $T-30$. FW will be treated as a single type for this analysis, but we will note any differences in the three stronger systems.

\section{Environmental conditions}

Certain environmental conditions have been proposed as necessary for TC formation (e.g., Gray 1968; Anthes 1982). Six conditions are mentioned most frequently: a preexisting cyclonic disturbance, SST greater than or equal to $26^{\circ} \mathrm{C}$, low environmental wind shear, a thermodynamic environment favorable for deep convection, plentiful midlevel moisture, and an environment supporting upper-level divergence via outflow channels. We focus on the first four conditions in the $30 \mathrm{~h}$ immediately preceding formation of the $20 \mathrm{TCs}$ identified here. Specifically, we evaluate SST, static stability, EL, CAPE, and deep-layer vertical shear of the horizontal wind. Thirty-hour type-composited averages of each variable are presented in Table 2.

\section{a. SST}

SST is considered one of the more important conditions for TC formation and development (Gray 1968; DeMaria et al. 2001). The average of the SST for the period of $T-30$ to $T-0$ is compared against the 

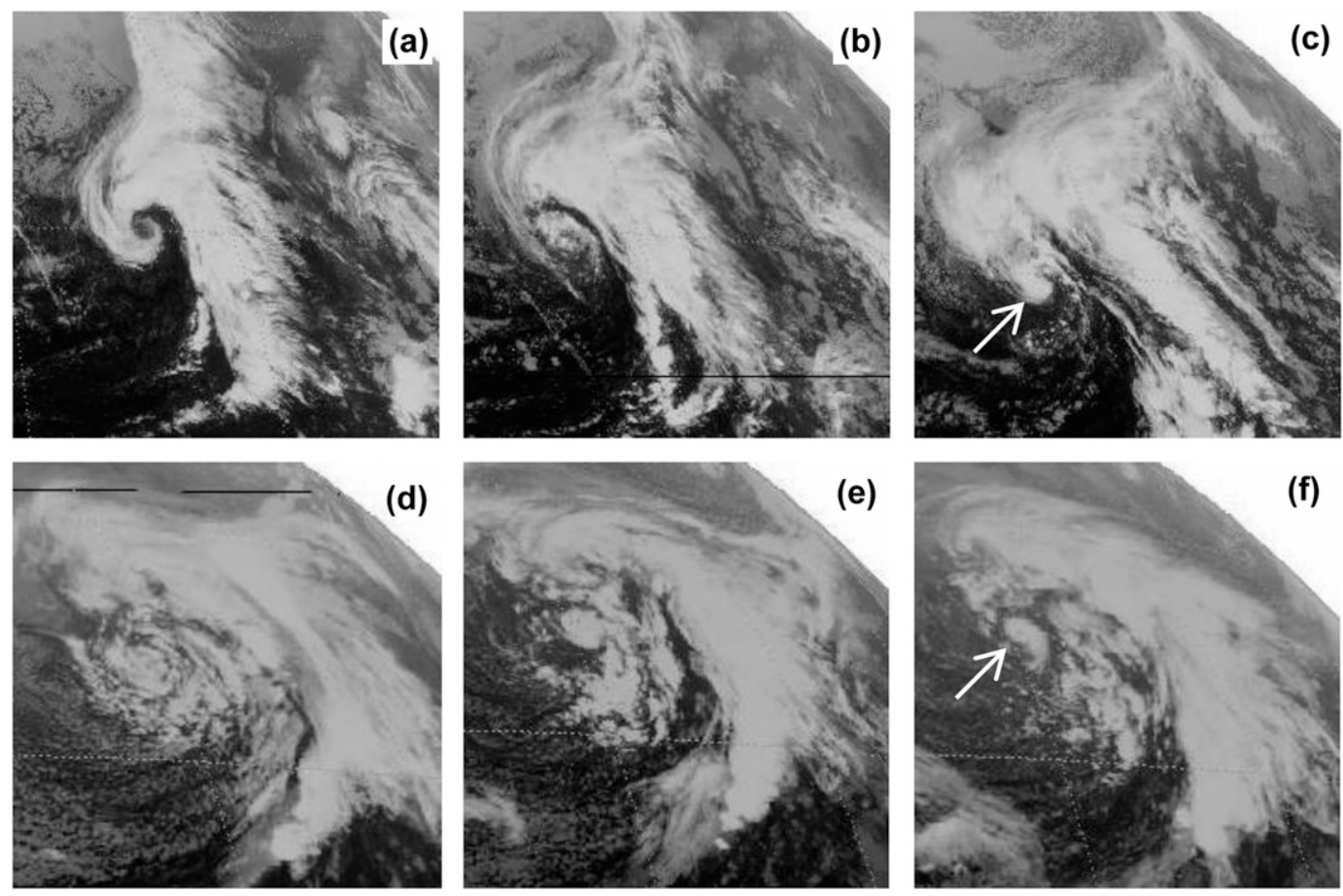

FIG. 5. The IR satellite imagery for (top) Olga (2001) and (bottom) Karl (1980). Systems are shown at (a),(d) $T-24$, (b),(e) $T-12$, and (c),(f) $T-0$. Arrows in (c) and (f) indicate the location of the TC.

1971-2000 mean SST anomaly for each system (Fig. 6). For the $30 \mathrm{~h}$ prior to formation, TW systems remained over SSTs warmer than $26^{\circ} \mathrm{C}$. TW systems developed over SSTs warmer than those for all nontropical precursors. Fourteen of 17 nontropical cases formed over average SSTs of less than $26^{\circ} \mathrm{C}$. Small SST variability was observed among $\mathrm{TW}\left(0.2^{\circ} \mathrm{C}\right)$ and $\mathrm{SL}\left(2.1^{\circ} \mathrm{C}\right)$ systems, whereas greater SST variability was observed among FS $\left(5.2^{\circ} \mathrm{C}\right)$ and $\mathrm{FW}\left(4.6^{\circ} \mathrm{C}\right)$ systems. Six of $10 \mathrm{FW}$ systems developed over SSTs averaging $23^{\circ}-25^{\circ} \mathrm{C}$. SST anomalies exceeded $0.2^{\circ} \mathrm{C}\left(0.5^{\circ} \mathrm{C}\right)$ for 10 (5) of the 20 systems. Only the FS systems Karl (1980) and Lili (1990) formed over SST anomalies less than $-0.3^{\circ} \mathrm{C}$. Twelve of the 20 systems were located over cooler SSTs at $T-0$ relative to $T-30$.

The high average SST and small range for TW systems follows the theory that a minimum SST threshold applies to TCs originating from tropical precursors (Palmén 1948; Gray 1968). The analysis also suggests both lower and upper SST limits to TC formation from baroclinic precursors. Frontal types were not observed over SST warmer than $27^{\circ} \mathrm{C}$. Either frontal systems do not track over warm SST, or there is an underlying thermodynamic reason for this threshold. In section $6 \mathrm{~b}$ we will provide an explanation for TC development over cooler SSTs.

Maximum potential intensity (MPI) is a theoretical upper limit on a TC's intensity. MPI models have been devised by Emanuel (1988), DeMaria and Kaplan (1994), and Holland (1997). Emanuel (1988) estimates MPI by modeling the TC as a Carnot heat engine. Holland (1997) estimates MPI by calculating the maximum pressure fall within the TC core caused by warming via latent heat release. Both approaches assume the

TABLE 2. Type-composited average values of the study variables over the $30 \mathrm{~h}$ prior to formation, plus values for Grace (2009). Columns from left to right are SST, EL, CAPE, static stability for $T_{\mathrm{UL}}$ of 200 and $300 \mathrm{hPa}$, and wind shear for the 850-200-and 850-300-hPa layers.

\begin{tabular}{|c|c|c|c|c|c|c|c|}
\hline Case & $\begin{array}{l}\text { SST } \\
\left({ }^{\circ} \mathrm{C}\right) \\
\end{array}$ & $\begin{array}{c}\mathrm{EL} \\
(\mathrm{hPa})\end{array}$ & $\begin{array}{c}\text { CAPE } \\
\left(\mathrm{J} \mathrm{kg}^{-1}\right)\end{array}$ & $\begin{array}{l}\text { 200-hPa static } \\
\text { stability }\left({ }^{\circ} \mathrm{C}\right)\end{array}$ & $\begin{array}{c}\text { 300-hPa static } \\
\text { stability }\left({ }^{\circ} \mathrm{C}\right)\end{array}$ & $\begin{array}{c}850-200-\mathrm{hPa} \\
\text { shear }\left(\mathrm{m} \mathrm{s}^{-1}\right)\end{array}$ & $\begin{array}{c}850-300-\mathrm{hPa} \\
\text { shear }\left(\mathrm{m} \mathrm{s}^{-1}\right)\end{array}$ \\
\hline TW & 27.0 & 194 & 1516 & -80.5 & -59.3 & 13.5 & 9.6 \\
\hline SL & 25.2 & 245 & 884 & -80.7 & -61.2 & 10.1 & 7.2 \\
\hline FS & 23.1 & 278 & 766 & -76.8 & -61.6 & 9.5 & 7.3 \\
\hline FW & 24.3 & 254 & 754 & -79.3 & -60.9 & 13.2 & 9.3 \\
\hline G09 & 21.6 & 321 & 423 & -72.7 & -60.1 & 6.4 & 5.6 \\
\hline
\end{tabular}




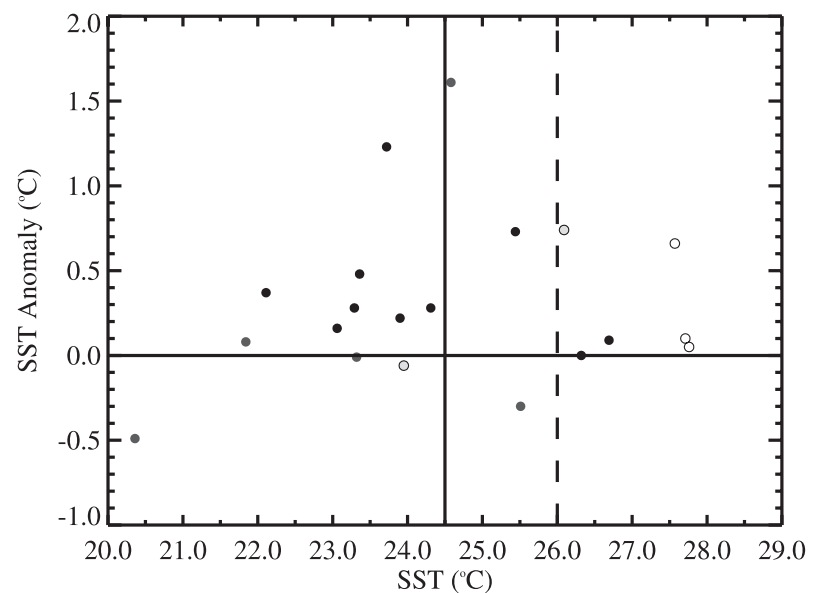

FIG. 6. Climatological SST anomalies (30-h average) plotted against observed SST (30-h average). Solid vertical line is the 20storm mean. Vertical dashed line is the Palmén (1948) SST threshold for TC development. Symbol shading as in Fig. 1.

TC can extract energy from only the ocean; Holland (1997) also assumes the TC is axisymmetric. Tonkin et al. (2000) found that both methods tend to underestimate MPI for North Atlantic TCs when SST $<26^{\circ} \mathrm{C}$.

Given the assumptions in these models, we use DeMaria and Kaplan (1994) to calculate MPI. They binned climatological SST in $1^{\circ} \mathrm{C}$ increments, then identified the strongest TC intensity (the MPI) for that SST bin. The authors derived the following relationship between SST and MPI:

$$
V=A+B e^{C\left(T-30^{\circ} \mathrm{C}\right)},
$$

where $V$ is the MPI $\left(\mathrm{m} \mathrm{s}^{-1}\right), T$ is the $\operatorname{SST}\left({ }^{\circ} \mathrm{C}\right)$, and $A, B$, and $C$ are constants $\left(A=28.2 \mathrm{~m} \mathrm{~s}^{-1}, B=55.8 \mathrm{~m} \mathrm{~s}^{-1}\right.$, and $\left.C=0.1813^{\circ} \mathrm{C}^{-1}\right)$. MPI was calculated based on $T-0$ SST and compared to the $T-0$ intensity (adjusted for the system's speed; Fig. 7). In general, lower MPI values were associated with higher cyclone intensities at the time of formation. More variation was noted in MPI for weaker systems. Though over warm SSTs, TW systems became minimal tropical storms.

Several caveats should be noted when interpreting these results. Equation (1) was based on climatological SST. We use actual SST in calculating the MPI; most SSTs were anomalously warm relative to climatology (Fig. 6). Observations of maximum intensity exceeding MPI values are likely a result of TC motion outpacing the rate of intensity reduction over a region of cool SSTs. About $14 \%$ of the TC sample used by DeMaria and Kaplan (1994) to develop Eq. (1) is contained within the specified region for this study, and only about half of those TCs developed between 1 October and 31 December.

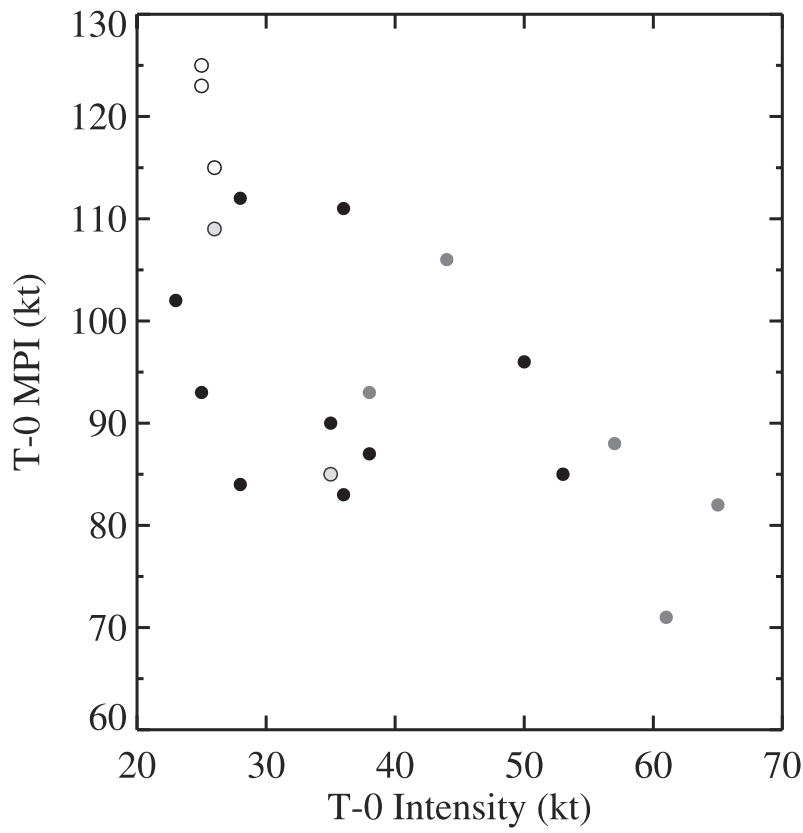

FIG. 7. MPI at $T-0$ compared to the $T-0$ intensity (adjusted for system motion). Symbol shading as in Fig. 1.

The formula represented by Eq. (1) would likely differ if a TC sample with these restrictions were used.

\section{b. Equilibrium level}

Estimation of EL pressure for surface-based parcels was a critical part of this analysis, since EL is a proxy for the maximum vertical extent of convection. For several FS and FW systems, 850- and/or 700-hPa temperatures were anomalously warm in comparison to the initial parcel conditions. A secondary EL was analyzed within that layer, resulting in a region of convective inhibition between 800 and $600 \mathrm{hPa}$. In most cases the parcel temperature exceeded the environmental profile at the next level, so parcels likely continued rising through this shallow warm layer to reach the colder layer above. Therefore, only the upper EL was analyzed here. Initial parcel conditions (pressure, temperature, and dewpoint depression) for each type are available in Table $\mathrm{S} 3$ online.

Lower pressure ELs were observed for TW systems than for nontropical precursors (Table 2; Table S1). Over $90 \%(65 / 72)$ of the quadrant ELs and 94\% (17/18) of the box ELs were less than $210 \mathrm{hPa}$. Dewpoint depressions were about $4^{\circ} \mathrm{C}$ for TW systems. The greater dewpoint depressions associated with TW led to lower lifting condensation level (LCL) pressures compared with the FS and FW systems. However, the environment aloft was sufficiently cold to produce ELs at relatively low pressures. EL variance between quadrants was minimal for the TW category. Opposite trends were observed 
for the two SL systems, likely due to the different directions of motion [north for Irma (1978), west for Lorenzo (2001)].

Box averages for FS (FW) systems ranged from 224 to $374 \mathrm{hPa}(200$ to $337 \mathrm{hPa})$. EL pressure increased over the 30 -h period for three of the five FS systems. ELs were monotonically increasing or decreasing for the weaker FW systems. The three strongest FW systems (Peter in 2003, Otto in 2004, and Vince in 2005) had separate periods of increasing and decreasing EL over the 30 -h period. EL varied greatly among quadrants for both FS and FW systems, producing no concrete trends. For five systems (all with nontropical origins) the EL in one quadrant changed by more than $130 \mathrm{hPa}$ in $30 \mathrm{~h}$. In all five cases, the environmental temperature profile at either $T-30$ or $T-0$ was approaching saturated neutrality. The EL at those times thus occurred at exceptionally high pressures $(900-700 \mathrm{hPa})$, producing a large $(T-30)-(T-0)$ difference. Dewpoint depressions were smallest for the FS systems and slightly larger for FW systems. Despite higher LCL pressures, in most cases the parcel temperature profile was only slightly warmer than the environment for its entire ascent, effectively increasing the EL pressure. Overall, nontropical precursors had lower EL heights than tropical precursors, suggesting a shallower vertical layer available to convection.

\section{c. $C A P E$}

Another method of analyzing the thermodynamic environment is via CAPE. Values were modest for the nontropical precursors in comparison to the tropical precursors (Table 2; Table S2). The box average for baroclinic precursors peaked at about $1500 \mathrm{~J} \mathrm{~kg}^{-1}$, while tropical precursors peaked at about $2000 \mathrm{~J} \mathrm{~kg}^{-1}$. The box-average CAPE with all three TW systems exceeded $1100 \mathrm{~J} \mathrm{~kg}^{-1}$ at all times, likely caused by a cold upper-level environment relative to parcel conditions and a lack of secondary ELs. As with the other three types, CAPE varied by as much as $1500 \mathrm{~J} \mathrm{~kg}^{-1}$ between the quadrants.

The box trends of CAPE followed the box trends of EL over the 30-h period with FS systems. Higher CAPE was calculated for Lili (1990) and Noel (2001) during that period than for Karl (1980), Lili (1984), and Delta (2005). CAPE of $700 \mathrm{~J} \mathrm{~kg}^{-1}$ or less was observed for four FS systems at $T-0$, a decrease in CAPE from $T-30$. For FW systems, CAPE increased in most of the quadrants from $T-30$ to $T-0$, and increased in the boxes for 8 of the 10 systems. The range of CAPE between quadrants might be expected to decrease between $T-30$ and $T-0$ if the environment becomes less baroclinic. Only 7 of 20 systems analyzed had decreasing ranges of CAPE over the 30-h study period, 3 of which were FS. This variability suggests that the thermodynamic environment in which these systems develop may still be baroclinic during the transition period.

For certain systems, substantial differences were observed within quadrants over the 30-h study period. The largest CAPE variations between consecutive analysis times appeared to be caused by two factors: storm motion inducing a shift in the center grid point and thermodynamic profiles approaching saturated neutrality. Center grid points for systems shifted by up to $5^{\circ}$ in latitude and $7.5^{\circ}$ in longitude in $30 \mathrm{~h}$. Such shifts can result in substantial differences in the calculated parcel and environmental temperature profiles, and thus CAPE values, when comparing consecutive times. Differences in quadrant ranges between $T-30$ and $T-0$ were especially large if a quadrant's thermodynamic profile was near saturated neutrality at one of the two analysis times (less CAPE) and was relatively unstable at the other time (greater CAPE).

To determine which factors were changing with CAPE, Spearman rank correlations were performed on CAPE and five parameters: the difference between the level of free convection (LFC) and EL, EL, LFC, LCL, and dewpoint depression (DD). Correlation coefficients are available in Table S4. For the LFC - EL difference, the secondary EL is used if two exist. For the EL, the upper EL alone was used. EL appeared to be changing most closely with CAPE for TW systems, though the LCL for the NW-SW-SE quadrants was also strongly linked. EL was less closely linked to CAPE for the nontropical types. For FS and FW, the most closely related factor is the LFC - EL difference. This is reasonable given the number of 900-700-hPa ELs present for these types. LCL and DD coefficients were also relatively large and significant for FW cases. This suggests that surface conditions may also affect those cases. Coefficients for FS cases are only significant in certain quadrants, indicating that the LFC - EL difference is most strongly linked for that type.

Evans and Guishard (2009) found higher CAPE (exceeding $1100 \mathrm{~J} \mathrm{~kg}^{-1}$ ) prior to subtropical cyclone formation. Within a typical TC, CAPE is relatively small. Warm-core development during TT may reduce CAPE, making the environment more characteristic of one associated with a TC.

\section{d. Static stability}

Static stability is another method of assessing whether the environment is capable of supporting deep convection. Environmental static stability was estimated using the following equation:

$$
\text { Static Stability }=T_{\mathrm{UL}}-T_{0.995 \text { sigma }},
$$


where $T_{\mathrm{UL}}$ represents an upper-level temperature and both temperatures are in degrees celsius. Both 200 and $300 \mathrm{hPa}$ were tested as $T_{\mathrm{UL}}$. Lesser (greater) values from the static stability calculation represent a less (more) stable thermodynamic environment.

Using $200 \mathrm{hPa}$ as the upper level, the observed FS and FW composites were more statically stable than the observed SL and TW composites (Table 2). The TW composite environment was least statically stable. Almost $2^{\circ} \mathrm{C}$ separated the FW and FS composites; FS systems were the most statically stable in this analysis. Static stability values were significantly altered, relatively among the four classification types, when the 300-hPa temperature was used as $T_{\mathrm{UL}}$. The three nontropical categories exhibited static stability values of $2^{\circ} \mathrm{C}$ less than the TW category. These differences can be understood in terms of tropopause height. Tropopause heights were likely higher for TW systems, producing lower stability in the 200-300-hPa layer. Lower-tropopause heights for the nontropical precursors, and especially for the FS type, lead to environmental instability being compressed into a shallower layer, which offsets the stabilizing effect of relatively low SST.

Reduced static stability has been observed in previous case studies of hybrid systems. Moore and Davis (1951) noted reduced static stabilities in Hurricane Able when using $300 \mathrm{hPa}$ as the upper level. Air temperatures at $300 \mathrm{hPa}$ were anomalously cool, and the disturbance was located over $25^{\circ} \mathrm{C}$ SSTs. Erickson (1967) detailed similar conditions during the formation of Dorothy (1966). Instability was concentrated in a shallow layer relative to the instability experienced by TCs in the deep tropics. A weather ship observed a 450-hPa temperature anomaly of $-7^{\circ} \mathrm{C}$ to the northwest of the developing system, which was over SSTs of $25^{\circ}-26^{\circ} \mathrm{C}$. In this study, the SSTs were similarly moderate in value and the 300-hPa temperature was typically cooler than climatology. At $T-6$ and $T-0$, the range for frontal system static stabilities was $2^{\circ} \mathrm{C}$, suggesting environments of similar instability near the time of transition. Reduced static stabilities may be indicative of the system interacting with the ambient atmosphere to produce a more tropical-like environment.

\section{e. Vertical wind shear}

The role of vertical shear of the horizontal wind (hereafter wind shear) during TC development has been studied extensively. Wind shear and SST are the most critical factors for predicting TC formation (DeMaria et al. 2001). Low wind shear was once thought necessary for TC formation (Gray 1968). In the last decade, a more complex relationship between TCs and shear was revealed. Bracken and Bosart (2000) observed that developing tropical depressions experienced moderate (average $10 \mathrm{~m} \mathrm{~s}^{-1}$ ) vertical wind shear. They proposed that shear is necessary to force synoptic-scale ascent and to organize the resulting convection. TC formation is considered unlikely for wind shear in excess of $15 \mathrm{~m} \mathrm{~s}^{-1}$. For shear in excess of $10 \mathrm{~m} \mathrm{~s}^{-1}$, TC formation is possible but the resulting system will likely struggle to intensify (DeMaria et al. 2001).

Table 2 contains 30-h-averaged vertical wind shear for both the 850-200- and 850-300-hPa layers. For the 850-200-hPa layer, average shear in excess of $10 \mathrm{~m} \mathrm{~s}^{-1}$ was observed for 13 systems, including all 3 TW systems and $8 \mathrm{FW}$ systems. Shear did not decrease below $10 \mathrm{~m} \mathrm{~s}^{-1}$ for six of the eight FW systems and one TW. Overall, shear experienced by FS systems was weak. Only one FS system (Delta 2005) had 30-h-average shear exceeding $10 \mathrm{~m} \mathrm{~s}^{-1}$. However, this system experienced two shear regimes: less than $7 \mathrm{~m} \mathrm{~s}^{-1}$ for $T-24$ to $T-12$, but greater than $15 \mathrm{~m} \mathrm{~s}^{-1}$ at other times. The 12-h period of weak shear prior to formation likely helped Delta to develop.

Wind shear magnitudes averaged $30 \%$ less in the 850-300-hPa layer compared to the 850-200-hPa layer. Only five systems were observed to have 30 -h-averaged environmental shear in excess of $10 \mathrm{~m} \mathrm{~s}^{-1}$, and only two (both FW) never decreased below that threshold at any time. FS systems again averaged the lowest shear in the 850-300-hPa layer, and TW the highest. The high shear experienced by TW systems in this region is interesting since weaker shear is thought to be important for typical tropical systems.

Davis and Bosart (2003) examined 10 cases of TT from the 2000 and 2001 seasons, including four TCs also studied here. They found that $900-200-\mathrm{hPa}$ shear decreased to less than $10 \mathrm{~m} \mathrm{~s}^{-1}$ at some point around the time of TT. A similar shear minimum was observed for most systems in this work. As noted earlier, however, for seven systems the 850-200-hPa wind shear never decreased below $10 \mathrm{~m} \mathrm{~s}^{-1}$ in the $30 \mathrm{~h}$ prior to formation. For two systems, $850-300-\mathrm{hPa}$ shear never decreased below $10 \mathrm{~m} \mathrm{~s}^{-1}$. Wind shear is not necessarily a limiting factor for TC formation in this region.

In addition to computing the average shear, $15^{\circ} \times 15^{\circ}$ shear fields were plotted and analyzed. A small area of weaker shear (less than $12.0 \mathrm{~m} \mathrm{~s}^{-1}$ ) was frequently present near the developing system. For all frontal systems, an area of lower shear was nearby sometime during the 30-h formation period, perhaps due to weak winds in the lingering upper-level cyclone. A local minimum was not observed for the TW cases. For TCs developing from nontropical precursors, this area of low shear may create a localized favorable environment within a broader unfavorable environment. 

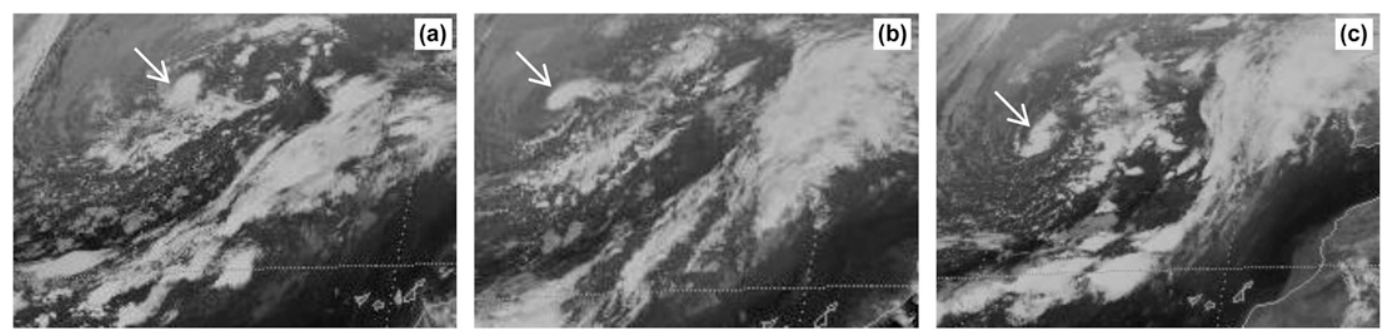

FIG. 8. Sequence of satellite imagery for the development of Grace (2009) at (a) $T-24$, (b) $T-12$, and (c) $T-0$. Arrows indicate the location of the developing TC.

\section{Case study: Tropical Storm Grace (2009)}

In early October 2009, a TC developed from a nearly stationary occluding low near the Azores. Figure 8 is a series of satellite images of the developing system. A frontal zone was still evident to the east of the cyclone throughout the period. At $T-24$ (Fig. 8a), convection began to coalesce at the center of the low. The convection had deepened and became more discrete by $T-12$, though scattered clouds were still apparent between the core system and the frontal zone (Fig. 8b). By $T-0$, the core convection completely separated from the frontal zone, and the circulation had acquired sufficient tropical characteristics to be classified as Tropical Storm (TS) Grace at 0600 UTC 4 October 2009 (Fig. 8c). Other examples of hybrid TCs can be found in HURDAT [e.g., Isaac (2006), Laura (2008)]. Tropical storm Grace is one example of a hybrid TC that existed within the region and time period of our study. Results derived from the main study set were tested with Grace.

Analysis of each variable was repeated for Grace, and 30 -h averages are presented in Table 2 . Vorticity magnitude and transition intensity placed Grace in the FW type, similar to the three strongest FW systems [Peter (2003), Otto (2004), and Vince (2005)]. SSTs under Grace were $21^{\circ}-22^{\circ} \mathrm{C}$, with small positive $\left(0.2^{\circ}-0.4^{\circ} \mathrm{C}\right)$ anomalies. At $T-0$, the MPI for Grace was $81 \mathrm{kt}$. Both the SST and MPI were low, but still consistent with other frontal systems.

Box ELs for Grace ranged from 400 to $275 \mathrm{hPa}$ and CAPEs from 44 to $730 \mathrm{~J} \mathrm{~kg}^{-1}$, most consistent with the colder FW systems. The NW quadrant tended to have the highest-pressure EL and the smallest CAPE at all times. From $T-30$ to $T-12$, the lowest-pressure ELs and the largest CAPE $\left(>1100 \mathrm{~J} \mathrm{~kg}^{-1}\right)$ were observed in southern quadrants. At $T-0$, CAPE had decreased to 300-700 J kg ${ }^{-1}$ among all quadrants. As was observed in both FS and FW systems, secondary ELs reduced CAPE values associated with Grace at some times. Consistent with the original study set, static stability depended on the choice of the upper level. Using $200 \mathrm{hPa}$ as the upper level indicated a highly statically stable environment comparable to FS systems. Using $300 \mathrm{hPa}$, the environment was much less statically stable, and was similar to the FW systems.

Wind shear remained less than $7.0 \mathrm{~m} \mathrm{~s}^{-1}$ at all times in the 850-300-hPa layer and from $T-30$ to $T-12$ in the 850-200-hPa layer. While this light shear was more consistent with the FS type, SSTs under Grace were cold. Weak shear may have been necessary to maintain the convection. Also, Grace's location in the far northeastern Atlantic basin likely contributed to the combination of FS and FW characteristics.

\section{Discussion}

A major forecasting problem particular to hybrid systems is identifying when a nontropical system becomes a TC. Microwave imagery enables forecasters to detect warm cores, and space-based scatterometers can estimate the surface wind field. However, criteria are rather subjective, and evaluation dependent on the availability of data. In satellite imagery, even at $T-0$ hybrid systems often appear to retain some nontropical characteristics, especially limited central convection and lingering frontal zones.

Some comments regarding the synoptic situation and environmental conditions for each type are provided below in section $6 \mathrm{a}$, in the hope that they will assist forecasters in identifying systems likely to develop into TCs. Figure 9 is a set of schematics for each type, showing the low-level center, surface pressure field and fronts, and 500-hPa heights. These diagrams are intended to be representative of the general pattern; specific features will differ for individual systems. In section $6 \mathrm{~b}$, a proposed formation mechanism in conditions of cool SST and high wind shear is presented.

\section{a. Forecasting hybrid TCs in the northeastern Atlantic}

TW systems (Fig. 9a) experience moderate to strong wind shear during development, but form over $27^{\circ}-28^{\circ} \mathrm{C}$ SSTs. Convection tends to be robust despite the shear and the presence of an upper-level cyclone or trough. 

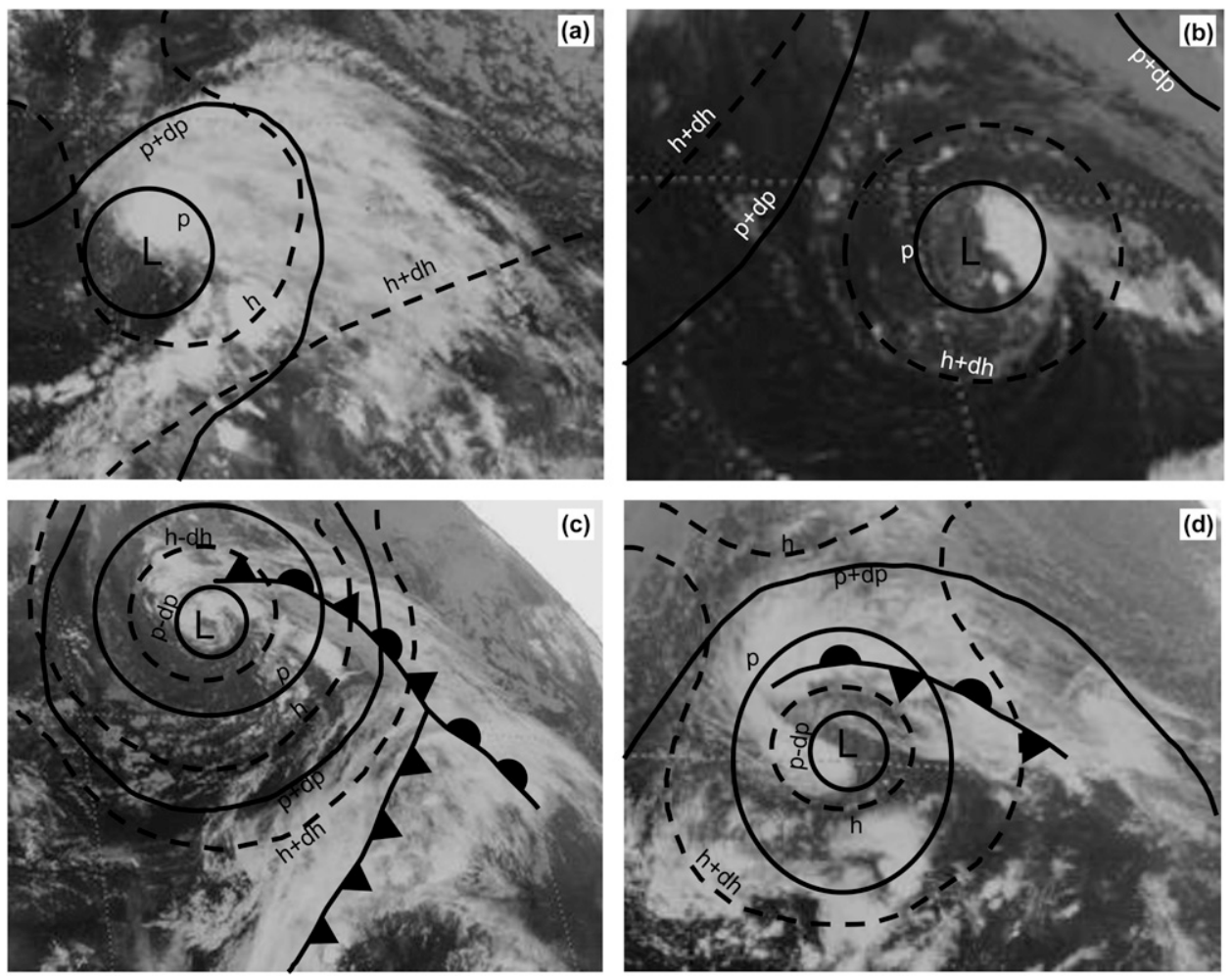

FIG. 9. Representative schematics for each type of system at $T-12$. Images are the same as in Fig. 4, but adjusted for contrast with the additional features. The $\mathrm{L}$ marks the surface center of each system where the TC is developing. Solid lines represent surface isobars and dashed lines represent 500-hPa isohypses. Additional features should be construed as a conceptual model of the environment within which each type transforms into a TC.

Depending on the location of the upper-level feature, it may reduce the ambient stability relative to the typical tropical atmosphere and create an environment favorable for upper-level divergence. If conditions are favorable after formation, these TCs can become minor hurricanes (categories 1 and 2).

From this study, SL systems (Fig. 9b) are found to be weak and short lived, and present a challenge in obtaining an accurate TC season count. Given the undistinguished lifetime and disorganized appearance in satellite imagery, it is possible that additional SL systems have formed, but are missing from the official TC record (e.g., Landsea et al. 2010). Moderate SST and reduced static stability appear to be key factors in SL development. Wind shear for the two systems in this study was initially weak, likely aiding convection.

FS systems (Fig. 9c) form from intense nontropical cyclones. Frontal structures are frequently still evident in satellite imagery; depending on the maturity of the system, cold and warm fronts may be visible. The surface and $500-\mathrm{hPa}$ centers are usually vertically stacked. At $500 \mathrm{hPa}$, the cyclone may be a cutoff low (if located in the southern part of the region) or part of a deep upperlevel trough in the westerlies. Wind shear with FS systems is weak, which is a positive contribution to TC formation that offsets the negative effect of relatively cool SSTs. Convective instability is strong in the lower layers of the developing system; with FS systems, convection surrounds the center by $T-12$. As mentioned in section $3 \mathrm{c}$, FS systems are close to peak intensity at $T-0$.

FW systems (Fig. 9d) are largely a weaker version of FS in synoptic pattern. Though they each vary widely with FW systems, the SSTs tend to be cooler and the wind shear tends to be higher than those found with other systems in this study. The higher shear may have contributed to the lack of organization of FW systems relative to FS systems. Both surface and 500-hPa lows are evident in the fields, though the surface system is weaker. Strong convective instability in the lower levels produces widespread convection. Unlike with FS systems, convection is often not completely banded around the low-level center of FW systems. Frontal structures are still evident in satellite imagery and take two forms. 


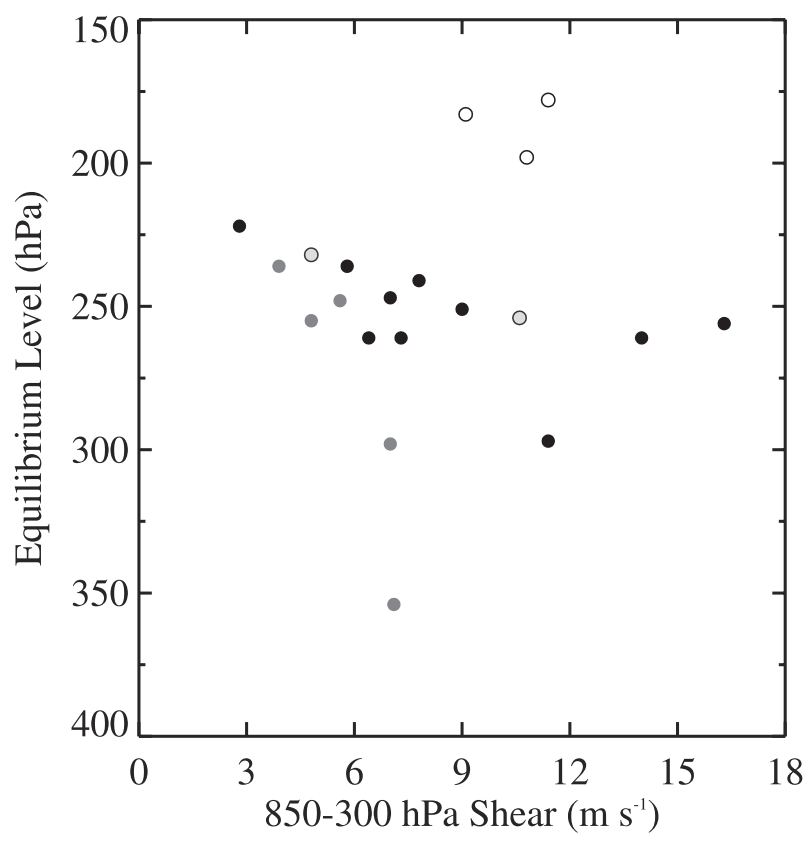

FIG. 10. The EL for each system at $T-12$ plotted against $850-300-\mathrm{hPa}$ shear at $T-12$. Symbol shading is as in Fig. 1.

Most common is the scenario shown in Fig. 9d: a stationary or occluded front arcs across the northern portion of the low. For other systems such as Olga (2001; Figs. 5a-c), the classic occluded frontal structure, with occluded, cold, and warm fronts, is still discernible.

\section{b. Proposed formation mechanism}

Davis and Bosart (2003) hypothesized that TC formation from a baroclinic precursor occurred when the occluded system tracked over SSTs warmer than $26^{\circ} \mathrm{C}$ for at least a day. Fifteen TCs formed over SSTs less than $26^{\circ} \mathrm{C}$, indicating that TT over cooler SSTs is not uncommon in this region. A comparison of the wind shear and stability analyses reveals a possible explanation for TC formation over cool SST and within high wind shear. Figure 10 is a plot of the EL and 850300-hPa wind shear at $T-12$. The TW systems are separate from the other three types at the top of Fig. 10, characterized by high ELs and moderate shear. For the three nontropical categories, there is an overall trend toward lower ELs in conjunction with higher wind shear; this trend is also observed within types.

What would cause the apparent link between lower ELs and higher wind shear? Given modest CAPE, shallow convection will occur where the EL is low, thus creating a shallow system. The reduced depth of convection associated with TCs from nontropical precursors limits the effects of $850-200-\mathrm{hPa}$ wind shear on those systems. If this shallow structure was maintained after
TT, it also may explain why decay predictions due to shear did not verify (e.g., for Epsilon and Zeta, both in 2005).

The Palmén (1948) SST threshold of $26^{\circ}-27^{\circ} \mathrm{C}$ is thought to be the minimum SST for supporting deep convection in the tropics. Baroclinic precursors have an advantage, however, because they are able to supplement air-sea energy fluxes with baroclinic instability. A recent modeling study (Nolan and Rappin 2008) suggested that sensitivity to wind shear is increased for TCs developing over high SSTs. Given the range of wind shear and SST in this study, it is possible that the presence of low SSTs may reduce the sensitivity of TCs to wind shear by inducing shallower convection.

\section{Conclusions}

This work examined TC formation events during the months of October-December over the northeastern Atlantic Ocean. No studies have looked specifically at this area despite recent activity. Between 1975 and 2010, 405 TCs were recorded in HURDAT. Ninety (22\%) achieved maximum winds of $35 \mathrm{kt}$ or greater during October-December (late season). Only 48 TCs (12\%) formed north of $20^{\circ} \mathrm{N}$ and east of $60^{\circ} \mathrm{W}$ (the northeastern Atlantic basin) during all months. The study set of 21 TCs represents $23 \%$ of late-season TCs and $44 \%$ of northeastern Atlantic TCs. Late-season TCs contribute significantly to the activity in this little-studied region, highlighting the need to understand these systems.

A classification scheme of four categories, one tropical (TW) and three nontropical (SL, FS, and FW), was developed using dynamic and thermodynamic criteria. The three nontropical categories fit within the broad SEC and strong TT categories. Eighteen of the 21 TCs examined in this study developed from nontropical precursors, and 16 developed from low pressure systems with frontal structures. Forecasting such hybrid TCs is challenging because they depart from the classical tropical development process. One of the goals of this study was to determine how environmental conditions in the pre-TC environments differed from the accepted conditions for TC formation. Conditions examined included a preexisting disturbance, SST, atmospheric instability, and wind shear.

A preexisting cyclonic disturbance was found in all cases, though the intensity varied. By early October, an extratropical cyclone appears to most often constitute the necessary precursor for TC formation over the study region. All systems with nontropical origins were observed to have stronger $500-\mathrm{hPa}$ local relative vorticity maxima than the systems with tropical origins. This finding implies that a certain degree of elevated cyclonic 
organization is necessary for a nontropical system to become a TC over the northeastern Atlantic Ocean. Relative vorticity alone has limited predictive capability for identifying systems likely to develop into TCs. An analysis of the vorticity field may indicate the environment most conducive for a system of a particular category to become a TC.

SSTs associated with the study sample of TCs varied from $20^{\circ}$ to $28^{\circ} \mathrm{C}$. Only six systems formed over SSTs exceeding $26^{\circ} \mathrm{C}$. Thermodynamic parameters appeared to be the best indicators of a favorable environment, but depart from the conditions usually associated with tropical cyclogenesis. Static stability (representing the buoyancy of the ambient atmosphere) was reduced for nontropical precursors when using $300 \mathrm{hPa}$ as the upper level, and for tropical precursors when using $200 \mathrm{hPa}$ as the upper level. Although the static stability analysis suggested ambient environments favorable for deep convection, CAPE and EL indicated modest, relatively shallow convection for TCs with nontropical origins. The presence of shallow convection appears to be verified by satellite imagery (Figs. 4b-d).

In the tropics, wind shear can be a good discriminator of developing and nondeveloping disturbances (McBride and Zehr 1981; DeMaria et al. 2001). In our study domain, wind shear is less useful, varying widely between systems. Deep-layer (850-200 hPa) wind shear exceeded $10 \mathrm{~m} \mathrm{~s}^{-1}$ for more than half the cases. Lowering the upper level to $300 \mathrm{hPa}$ yields markedly reduced shear in most cases. In cases of large-scale strong wind shear, the local environment can be relatively hospitable to the cyclone.

Much work is yet to be done with respect to hybrid TCs. This study focused on the northeastern Atlantic basin during the last three months of the year. Hybrid TCs have been observed throughout the Atlantic hurricane season, especially between the U.S. east coast and Bermuda. Expanded geographical and temporal criteria would increase the sample of hybrid systems. Comparing these results to other regions would show whether late-season northeastern Atlantic systems are similar to other hybrid TCs. As mentioned in section 6, hybrid TCs derive energy from both baroclinicity and air-sea fluxes. Understanding the balance between these sources may help to forecast intensity changes of hybrid systems.

Davis and Bosart (2004) state that forecasting TT is largely a matter of predicting the onset of a favorable environment. Before forecasting TT, however, the conditions constituting a favorable environment must be known. SST and deep-layer wind shear are generally emphasized in genesis and intensity models. Based on this research, SST and deep-layer wind shear are not consistent predictors for the formation of late-season TCs from nontropical origins. Over the northeastern Atlantic Ocean, the convective environment may be a better predictor of TC formation than SST and wind shear. Attention should be focused on systems in environments of low static stability and with a nearby $850-300-\mathrm{hPa}$ shear minimum.

Acknowledgments. Comments from three anonymous reviewers greatly improved the manuscript. The first author was supported by an American Meteorological Society Graduate Fellowship from NOAA's Climate Prediction Center and a Distinguished University Fellowship from The Ohio State University. NCEPNCAR reanalysis data were provided by the NOAA/ OAR/ESRL PSD, Boulder, Colorado, from their web site (http://www.esrl.noaa.gov/psd/). Satellite imagery was provided by NOAA/NCDC through the Global ISCCP B1 Browse System (http://www.ncdc.noaa.gov/ gibbs/). HURDAT data were provided by AOML's Hurricane Research Division, available in various formats online (http://www.aoml.noaa.gov/hrd/hurdat/Data_ Storm.html).

\section{REFERENCES}

Anthes, R. A., 1982: Tropical Cyclones: Their Evolution, Structure, and Effects. Meteor. Monogr., No. 41, Amer. Meteor. Soc., 208 pp.

Berg, R. J., and L. A. Avila, 2011: Atlantic hurricane season of 2009. Mon. Wea. Rev., 139, 1049-1069.

Beven, J. L., II, S. R. Stewart, M. B. Lawrence, L. A. Avila, J. L. Franklin, and R. J. Pasch, 2003: Atlantic hurricane season of 2001. Mon. Wea. Rev., 131, 1454-1484.

_- and Coauthors, 2008: Atlantic hurricane season of 2005. Mon. Wea. Rev., 136, 1109-1173.

Bosart, L. F., and J. A. Bartlo, 1991: Tropical storm formation in a baroclinic environment. Mon. Wea. Rev., 119, 1979-2013.

Bracken, E., and L. F. Bosart, 2000: The role of synoptic-scale flow during tropical cyclogenesis over the North Atlantic Ocean. Mon. Wea. Rev., 128, 353-376.

Davis, C. A., and L. F. Bosart, 2003: Baroclinically induced tropical cyclogenesis. Mon. Wea. Rev., 131, 2730-2747.

—, and — 2004: The TT problem: Forecasting the tropical transition of cyclones. Bull. Amer. Meteor. Soc., 85, 1657-1662.

DeMaria, M., and J. Kaplan, 1994: Sea surface temperature and the maximum intensity of Atlantic tropical cyclones. J. Climate, 7, $1325-1334$.

— J. A. Knaff, and B. H. Connell, 2001: A tropical cyclone genesis parameter for the tropical Atlantic. Wea. Forecasting, 16, 219-233.

Dvorak, V. F., 1975: Tropical cyclone intensity analysis and forecasting from satellite imagery. Mon. Wea. Rev., 103, 420-430.

Emanuel, K. A., 1986: An air-sea interaction for tropical cyclones. Part I: Steady-state maintenance. J. Atmos. Sci., 43, 585-604.

, 1988: The maximum intensity of hurricanes. J. Atmos. Sci., 45, 1143-1155.

, 1991: The theory of hurricanes. Annu. Rev. Fluid Mech., 23, 179-196.

Erickson, C. O., 1967: Some aspects of the development of Hurricane Dorothy. Mon. Wea. Rev., 95, 121-130. 
Evans, J. L., and M. P. Guishard, 2009: Atlantic subtropical storms. Part I: Diagnostic criteria and composite analysis. Mon. Wea. Rev., 137, 2065-2080.

Franklin, J. L., L. A. Avila, J. L. Beven II, M. B. Lawrence, R. J. Pasch, and S. R. Stewart, 2001: Atlantic hurricane season of 2000. Mon. Wea. Rev., 129, 3037-3056.

Gray, W. M., 1968: Global view of the origin of tropical disturbances and storms. Mon. Wea. Rev., 96, 669-700.

Hart, R. E., 2003: A cyclone phase space derived from thermal wind and thermal asymmetry. Mon. Wea. Rev., 131, 585-616.

Hebert, P. H., and K. O. Poteat, 1975: A satellite classification technique for subtropical cyclones. NOAA Tech. Memo. NWS SR-83, 25 pp.

Holland, G. J., 1997: The maximum potential intensity of tropical cyclones. J. Atmos. Sci., 54, 2519-2525.

Hulme, A. L., and J. E. Martin, 2009a: Synoptic and frontal-scale influences on tropical transition events in the Atlantic basin. Part I: A six-case survey. Mon. Wea. Rev., 137, 3605-3625.

$\longrightarrow$, and —, 2009b: Synoptic and frontal-scale influences on tropical transition events in the Atlantic basin. Part II: Tropical transition of Hurricane Karen. Mon. Wea. Rev., 137, 3626-3650.

Jarvinen, B. R., C. J. Neumann, and M. A. S. Davis, 1984: A tropical cyclone data tape for the North Atlantic basin, 18861983: Contents, limitations, and uses. NOAA Tech. Memo. NWS NHC 22, 24 pp.

Kalnay, E., and Coauthors, 1996: The NCEP/NCAR 40-Year Reanalysis Project. Bull. Amer. Meteor. Soc., 77, 437-471.

Kitabatake, N., 2008: Extratropical transition of tropical cyclones in the western North Pacific: Their frontal evolution. Mon. Wea. Rev., 136, 2066-2090.

Landsea, C. W., G. A. Vecchi, L. Bengtsson, and T. R. Knutson, 2010: Impact of duration thresholds on Atlantic tropical cyclone counts. J. Climate, 23, 2508-2519.

Lawrence, M. B., 1977: Atlantic hurricane season of 1976. Mon. Wea. Rev., 105, 497-507.

- and J. M. Pelissier, 1981: Atlantic hurricane season of 1980. Mon. Wea. Rev., 109, 1567-1582.

, B. M. Mayfield, L. A. Avila, R. J. Pasch, and E. N. Rappaport, 1998: Atlantic hurricane season of 1995. Mon. Wea. Rev., 126, 1124-1151.
McBride, J. L., and R. Zehr, 1981: Observational analysis of tropical cyclone formation. Part II: Comparison of nondeveloping versus developing systems. J. Atmos. Sci., 38, 1132-1151.

McTaggart-Cowan, R., L. F. Bosart, C. A. Davis, E. H. Atallah, J. R. Gyakum, and K. A. Emanuel, 2006a: Analysis of Hurricane Catarina (2004). Mon. Wea. Rev., 134, 3029-3053.

— _ _ J. R. Gyakum, and E. H. Atallah, 2006b: Hurricane Juan (2003). Part II: Forecasting and numerical simulation. Mon. Wea. Rev., 134, 1748-1771.

—, G. D. Deane, L. F. Bosart, C. A. Davis, and T. J. Galarneau Jr., 2008: Climatology of tropical cyclogenesis in the North Atlantic (1948-2004). Mon. Wea. Rev., 136, 1284-1304.

Moore, P. L., and W. R. Davis, 1951: A preseason hurricane of subtropical origin. Mon. Wea. Rev., 79, 189-195.

Nolan, D. S., and E. D. Rappin, 2008: Increased sensitivity of tropical cyclogenesis to wind shear in higher SST environments. Geophys. Res. Lett., 35, L14805, doi:10.1029/2008GL034147.

Palmén, E. H., 1948: On the formation and structure of tropical hurricanes. Geophysica, 3, 26-38.

Pasch, R. J., and L. A. Avila, 1992: Atlantic hurricane season of 1991. Mon. Wea. Rev., 120, 2671-2687.

Pezza, A. B., and I. Simmonds, 2005: The first South Atlantic hurricane: Unprecedented blocking, low shear and climate change. Geophys. Res. Lett., 32, L15712, doi:10.1029/2005GL023390.

Reynolds, R. W., N. A. Rayner, T. M. Smith, D. C. Stokes, and W. Wang, 2002: An improved in situ and satellite SST analysis for climate. J. Climate, 15, 1609-1625.

Simpson, R. H., 1952: Evolution of the Kona storm, a subtropical cyclone. J. Meteor., 9, 24-35.

_ , and J. R. Hope, 1972: Atlantic hurricane season of 1971. Mon. Wea. Rev., 100, 256-267.

Smith, T. M., R. W. Reynolds, T. C. Peterson, and J. Lawrimore, 2008: Improvements to NOAA's historical merged landocean surface temperature analysis (1880-2006). J. Climate, 21, 2283-2296.

Tonkin, H., G. J. Holland, N. Holbrook, and A. Henderson-Sellers, 2000: An evaluation of thermodynamic estimates of climatological maximum potential tropical cyclone intensity. Mon. Wea. Rev., 128, 746-762. 